\title{
Mechanism Investigation of the Improvement of Chang Run Tong on the Colonic Remodeling in Streptozotocin-Induced Diabetic Rats
}

\author{
Hong Sha, ${ }_{1}^{1}$ Dong Zhao, ${ }^{1}$ Xiaolin Tong, ${ }^{2}$ Hans Gregersen, ${ }^{3}$ and Jingbo Zhao ${ }^{3,4}$ \\ ${ }^{1}$ China-Japan Hospital, Beijing 100029, China \\ ${ }^{2}$ Guang'anmen Hospital, China Academy of Chinese Medical Sciences, Beijing 100053, China \\ ${ }^{3}$ Bioengineering College of Chongqing University, Chongqing 400044, China \\ ${ }^{4}$ Department of Clinical Medicine, Aarhus University, 8200 Aarhus N, Denmark
}

Correspondence should be addressed to Jingbo Zhao; jingbo.zhao@clin.au.dk

Received 13 July 2015; Revised 29 September 2015; Accepted 30 September 2015

Academic Editor: Mark A. Yorek

Copyright (C) 2016 Hong Sha et al. This is an open access article distributed under the Creative Commons Attribution License, which permits unrestricted use, distribution, and reproduction in any medium, provided the original work is properly cited.

Previous study demonstrated that Chang Run Tong (CRT) could partly restore the colon remodeling in streptozotocin- (STZ-) induced diabetic rats. Here we investigated the mechanisms of such effects of CRT. Diabetes was induced by a single injection of $40 \mathrm{mg} / \mathrm{kg}$ of STZ. CRT was poured into the stomach by gastric lavage once daily for 60 days. The remodeling parameters were obtained from diabetic (DM), CRT treated diabetic (T1, $50 \mathrm{~g} / \mathrm{kg} ; \mathrm{T} 2,25 \mathrm{~g} / \mathrm{kg}$ ), and normal (Con) rats. Expressions of advanced glycation end product (AGE), AGE receptor, transforming growth factor- $\beta 1$ (TGF- $\beta 1$ ), and TGF- $\beta 1$ receptor in the colon wall were immunochemically detected and quantitatively analyzed. The association between the expressions of those proteins and the remodeling parameters was analyzed. The expressions of those proteins were significantly higher in different colon layers in the DM group $(P<0.05, P<0.01)$ and highly correlated to the remodeling parameters. Furthermore, the expressions of those proteins were significantly decreased in the T1 group $(P<0.05, P<0.01)$ but not in the T2 group $(P>0.05)$. The corrective effect on the expressions of those proteins is likely to be one molecular pathway for the improvement of CRT on the diabetes-induced colon remodeling.

\section{Introduction}

Constipation is very common in the general population [1] (Belsey et al., 2010) and affects the quality of human life [2]. Colonic and rectal sensory-motor function and biomechanical properties are now strongly implicated in the pathogenesis of constipation [3,4]. However, the pathophysiological mechanisms underlying chronic constipation remain to be explored $[5,6]$. Furthermore constipation is difficult to treat and has a high recurrence rate $[7,8]$.

The traditional Chinese medicine has good clinical effects on constipation [9]. During the past several years, the authors have through clinical observation found that the Chang Run Tong (CRT) produced by China-Japan Friendship Hospital could effectively treat senile constipation. From Chinese medicine point of view, CRT regulates qi, relieves stagnation, and lubricates the bowel. However, from the Western medicine point of view, the mechanism of CRT in the treatment of constipation is unclear.

The gastrointestinal (GI) tract is functionally subjected to dimensional changes. Hence, biomechanical properties such as the stress-strain relationship are of particular importance [10]. The remodeling of the mechanical properties reflects the changes in the tissue structure that determine a specific motor dysfunction. A previous study has demonstrated that experimental diabetes could induce colon morphological and biomechanical remodeling [11]. Following the development of diabetes, the colonic wall became thicker and the stiffness of the wall increased in a time-dependent manner. Such remodeling plays an important role in diabetic GI complications, including constipation [12]. Therefore, the streptozotocin-induced diabetic rat model is a good model 
to study the effect of drugs in the treatment of constipation on the morphological and biomechanical remodeling of the GI tract caused by diseases. Using this model, we recently demonstrated that CRT could partly restore the morphometric and biomechanical remodeling of colon in streptozotocin(STZ-) induced diabetic rats [13]. However the molecular pathways of CRT effect are unclear.

Advanced glycation end products (AGEs) are formed physiologically, increased with aging, and accelerated in diabetes [14]. AGEs can lead to structural and functional changes by direct target protein or through their receptor (RAGE) [15]. AGEs and RAGE have been demonstrated to play an important role in diabetic complications including the complications of the gastrointestinal tract [16]. TGF- $\beta 1$ has been considered to be core factor in the occurrence and development of diabetic nephropathy (DN) $[17,18]$. In recent years, the relationship between TGF- $\beta 1$ and other diabetic complications has been gradually noticed $[19,20]$. But there is lack of study about the relationship between TGF- $\beta 1$ and TGF$\beta 1$ receptor with the diabetic colonic histomorphological and biomechanical remodeling. Some studies have demonstrated that the association existed in the expressions of AGE/RAGE and TGF- $\beta$ during the development of diabetes $[21,22]$.

In order to investigate the mechanism of CRT in the improvement on the morphometric and biomechanical remodeling of the colon in streptozotocin- (STZ-) induced diabetic rats, the expressions of advanced glycation end product (AGE), AGE receptor (RAGE), transforming growth factor- $\beta 1$ (TGF- $\beta 1$ ), and TGF- $\beta$ receptor were detected in the colon wall. The association between those proteins expression and the histomorphometric and biomechanical parameters was analyzed as well.

\section{Materials and Methods}

2.1. Animal Model and Groups. Forty male Sprague-Dawley rats weighing 220-250 g were included in this study. Thirty rats were made diabetic by a single tail-vein injection of $40 \mathrm{mg} / \mathrm{kg}$ STZ (Sigma-Aldrich, China). This dose of STZ resulted in a random blood glucose level $(\geq 16.7 \mathrm{mmol} / \mathrm{L})$ in $90 \%$ of the rats $7 \mathrm{~d}$ after injection. The remaining $10 \%$ of rats were excluded from this study. Twenty-seven STZ-induced diabetic rats were subdivided into three groups $(n=9$ in each group), namely, the diabetic control group (DM), the high-dose CRT group (T1), and the low-dose CRT group (T2). Another ten rats of similar age and body weight from the same vendor were used as the nondiabetic control group (Con).

2.2. Drugs and Administration Methods. CRT is composed of Radix Angelicae Sinensis, Radix Cyathulae, Herba Cistanches, Rhizoma Alismatis, Rhizoma Cimicifugae, Fructus Aurantii Immaturus, Rhizoma Atractylodis Macrocephalae, Semen Arecae Prepareta, and hemp seed provided by China-Japan Hospital, The Ministry of Health of the People's Republic of China. The medicine was directly injected into the stomach lumen by gastric gavage once daily from the beginning of the experiment. The dosage was $50 \mathrm{~g} / \mathrm{kg} /$ day for $\mathrm{T} 1$ and
$25 \mathrm{~g} / \mathrm{kg} / \mathrm{day}$ for T2. The rats of the DM and Con groups were only given physiological saline.

2.3. Experimental Procedures and Sampling. The body weight and blood glucose levels were measured at 2-week intervals after the start of the experiment. The experimental period was $60 \mathrm{~d}$. At the ending of the experiment, the rats fasted overnight and then were anesthetized with $4 \%$ chloral hydrate $(10 \mathrm{~mL} / \mathrm{kg}$, ip). Following laparotomy, the whole colon was harvested. After the lumen of the segments was gently cleaned with saline, the length and the wet weight were measured. The colonic segment was divided into three parts: A $2 \mathrm{~cm}$ long tissue was cut from proximal end of the segments and fixed in $10 \%$ formalin for immunohistochemistry examination. Then a $1 \mathrm{~cm}$ long part was cut and used for the zerostress state experiment and the remaining part was used for the distension test. The results of zero-stress state and the distension test have been reported in our previous paper [13]. The parameters of morphometric properties, residual strains, and stress-strain of the wall in colonic segments were adopted from our previous paper [13] and used for correlation analysis with the expressions of different proteins used in the present paper.

\subsection{Immunohistochemistry Staining}

2.4.1. Tissue Pretreatment. The tissue samples for immunohistochemistry were fixed in $10 \%$ phosphate-buffered formalin for $24 \mathrm{~h}$ and embedded in paraffin. Five-micron sections were cut perpendicular to the mucosa surface and placed in a water bath at $40^{\circ} \mathrm{C}$. Thereafter, sections were transferred onto pretreated microscopic slides which electrostatically attracted formalin fixed tissue and bound them to the slides. After drying the slides completely at room temperature, they were treated in an oven at $37^{\circ} \mathrm{C}$ overnight to enhance the attachment of tissue to the slides. The sections were deparaffinized two times in xylene, $15 \mathrm{~min}$ per time, and rehydrated in $100 \%, 95 \%, 90 \%, 80 \%, 70 \%, 60 \%$, and $50 \%$ ethanol two times, respectively, 3 sec per time, followed by rinsing for $10 \mathrm{~min}$ and washing in $0.01 \mathrm{M}$ PBS (pH 7.4).

2.4.2. AGE. After treatment with $\mathrm{H}_{2} \mathrm{O}_{2}$ (3\% in ethanol, room temperature, $15 \mathrm{~min})$ and proteinase $\mathrm{K}(100 \mu \mathrm{g} / \mathrm{mL}, 100 \mu \mathrm{L}$, $\left.37^{\circ} \mathrm{C}, 20 \mathrm{~min}\right)$, the sections were incubated with 5\% BSA-PBS buffer (room temperature, $30 \mathrm{~min}$ ) for blocking nonspecific staining. Afterwards, the sections were incubated with the primary anti-AGE antibody (Abcam, $1: 100$, diluted in $1 \%$ BSA-PBS) or normal mouse IgG $(250 \mu \mathrm{g} / \mathrm{mL})$ pretreated with excessive CML $(1: 250$, diluted in $1 \%$ BSA-PBS, negative control) over night at $4^{\circ} \mathrm{C}$. The sections were then washed and incubated with LINK (biotinylated anti-rabbit and anti-mouse immunoglobulin) and streptavidin peroxidase (streptavidin conjugated with horseradish peroxidase), respectively, at room temperature for $10 \mathrm{~min}$ (both are part of reagents of LSAB2 System-HRP, products of Dako Company, Denmark). Then the peroxidase activity was visualized by incubating the sections in substrate working solution containing hydrogen peroxide and $3,3^{\prime}$-diaminobenzidine 
tetrahydrochloride at room temperature for $5 \mathrm{~min}$. The sections were rinsed for $10 \mathrm{~min}$, counterstained with Mayer hematoxylin for $1 \mathrm{~min}$, treated in $\mathrm{HCl}$-ethanol for $3 \mathrm{sec}$, and dehydrated in $80 \%, 90 \%, 95 \%$, and $100 \%$ ethanol for $3 \mathrm{sec}$, respectively. Then the slides were immersed in xylene for 15 min two times and mounted.

2.4.3. RAGE. The primary anti-RAGE antibody was produced in rabbits immunized with a synthetic peptide corresponding to a sequence at the N-terminal of human RAGE (Sigma). Only two amino acids are different from the related rat sequence. Instead of treating sections with proteinase $\mathrm{K}$ for RAGE immunostaining, the sections were boiled in $10 \mathrm{mM}$ citrate buffer ( $\mathrm{pH}$ 6.0) for $18 \mathrm{~min}$ for retrieving antigen. Normal rat lung was used as positive control since RAGE is highly expressed in the lung [23]. The primary antibody was diluted $(1: 80)$ with $1 \%$ BSA-PBS and normal rabbit serum (diluted $1: 60$ ) pretreated with excessive soluble RAGE was used as negative control. Other processes were similar to the AGE immunostaining.

2.4.4. TGF- $\beta 1$ and TGF- $\beta 1$ Receptor. The primary TGF- $\beta 1$ antibody (BA0290) and TGF- $\beta 1$ receptor antibody (BA05262) were obtained from Wuhan Boster Biological Engineering Co., Ltd. They were all diluted $(1: 100)$ with $1 \%$ BSA-PBS. The second antibody is HRP-goat anti-rabbit IgG and was diluted $(1: 150)$ with $1 \%$ BSA-PBS. The sections were placed in $3 \% \mathrm{H}_{2} \mathrm{O}_{2}$ (AR1108) at room temperature for 5-10 minutes to inactivate endogenous enzymes. The sections were rinsed with distilled water for 3 times. Hot fix antigen: The sections were immersed in $0.01 \mathrm{M}$ citrate buffer (AR0024, $\mathrm{pH}$ 6.0) or 0.02 M PBS (AR0030, pH 7.2-7.6) and heated to boiling using electricity or microwave for retrieving antigen. This process was repeated one or two times and the interval is 5-10 minutes. Then the slides were naturally cooled to room temperature. The sections were incubated with 5\% BSA blocking solution (AR0004) $\left(37^{\circ} \mathrm{C}, 30\right.$ minutes) for blocking nonspecific staining. Then the excess liquid was shanked off from the slides (do not wash) and incubated with diluted primary antibody over night at $4^{\circ} \mathrm{C}$ or 2 hours at $37^{\circ} \mathrm{C}$. The slides were rinsed with PBS ( $\mathrm{pH}$ 7.2-7.6) for 3 times (each time lasts 5 minutes). Then the slides were incubated with corresponding second antibodies $\left(37^{\circ} \mathrm{C}, 30\right.$ minutes). The slides were rinsed again for 3 times (each time lasts 5 minutes). The slides were incubated with $\mathrm{SABC}\left(37^{\circ} \mathrm{C}, 30\right.$ minutes) and washed for 4 times (each time lasts 5 minutes) with PBS ( $\mathrm{pH}$ 7.2-7.6). Then the peroxidase activity was visualized by incubating the sections with $D A B$ visualized kit (AR1022, taking 1 drop from each of $\mathrm{A}, \mathrm{B}$, and $\mathrm{C}$ reagent and mixing into $1 \mathrm{~mL}$ of distilled water) for about 15 minutes at room temperature. The slides were washed with distilled water and counterstained with hematoxylin (AR0005). Then the slides were dehydrated, transparent, and mounted.

2.4.5. Image Analysis. AGE, RAGE, TGF- $\beta 1$, and TGF- $\beta 1$ receptor are shown brown staining, but such color does not appear in the negative control slides, indicating that the staining is specific. To minimize errors, 6 to 10 photographs from different locations of the same layer in each slide were randomly taken. After that, different parts were saved as individual image files. The region of interest (ROI) was defined using Sigmascan Pro 4.0 image analysis software. The color due to $3,3^{\prime}$-diaminobenzidine staining was distinguished in the ROI using intensity thresholds. Finally the images were exported as binary images. The total area and area fraction of AGE, RAGE, TGF- $\beta 1$, and TGF- $\beta 1$ receptor positive staining were calculated by a Matlab program (Matlab 6.5, The MathWorks Inc., USA). Then the fraction of AGE, RAGE, TGF$\beta 1$, and TGF- $\beta 1$ receptor in mucosa, muscle, and submucosa layers were computed as fraction of protein expressions = immunopositive area/total measured area.

2.5. Statistical Analysis. The data were representative of a normal distribution and accordingly the results were expressed as means \pm SEM. Student's $t$-test and analysis of variance (ANOVA) were used to detect differences between parameters and groups (Sigmastat 2.0). Linear regression analysis was used to demonstrate possible association between the AGE, RAGE, TGF- $\beta 1$, and TGF- $\beta 1$ receptor expressions and histomorphometric and biomechanical parameters. The results were regarded as significant when $P<0.05$.

\section{Results}

3.1. General Data and Morphometry Data. The blood glucose, body weight, the wet weight per unit length, no-load wall thickness, and cross section wall area measured at the end of the experiment are shown in Table 1. The blood glucose level was about 4 -fold higher in the DM group compared with that of the Con group $(P<0.01)$. The body weight in the DM group was nearly $50 \%$ lower than that in the Con Group. Compared with the DM group, the blood glucose level in the T1 group $(P<0.05)$ was lower but that in the T2 group $(P>0.05)$ was higher. The body weight did not differ among the $\mathrm{DM}, \mathrm{T} 1$, and $\mathrm{T} 2$ groups $(P>0.05)$. The wet weight per unit length, no-load wall thickness, and cross section wall area of the colonic segments were significantly higher in the diabetic group compared with those of the Con group $(P<0.01)$. After treatment with $\mathrm{Tl}$, these parameters significantly decreased in the two segments $(P<0.05$ and $P<0.01)$; however, they did not significantly change in the T2 group $(P>0.05)$ with the exception of the wall thickness $(P<0.05)$.

3.2. Biomechanical Data. The biomechanical parameters of the colon segment obtained from previous study [13] were shown in Table 2 . The opening angles were significantly higher in the DM group compared with those in the Con group $(P<0.01)$. Treatment with a high dosage of CRT decreased the opening angle significantly $(P<0.05)$; the opening angle did not change in the T2 group $(P>0.05)$. A similar trend was found for the inner and outer residual strains; that is, the absolute values of the residual strain were significantly higher in the DM group compared with those in the Con group $(P<0.05, P<0.01)$. Treatment with a high dosage of CRT (T1 group) partially reversed the changes 
TABLE 1: Parameters of glucose, body weight, and morphometry of colon.

\begin{tabular}{|c|c|c|c|c|}
\hline & Con & $\mathrm{DM}$ & $\mathrm{T} 1$ & $\mathrm{~T} 2$ \\
\hline Body weight (g) & $443.69 \pm 5.01$ & $231.22 \pm 5.05^{* *}$ & $268.33 \pm 6.23^{* *}$ & $237.11 \pm 3.75^{* *}$ \\
\hline Blood glucose $(\mathrm{mmol} / \mathrm{L})$ & $5.06 \pm 0.04$ & $30.23 \pm 0.41^{* *}$ & $24.04 \pm 0.56^{* * \#}$ & $32.21 \pm 0.33^{* *}$ \\
\hline Wall thickness (mm) & $0.98 \pm 0.05$ & $1.23 \pm 0.04^{* *}$ & $1.13 \pm 0.05^{* \#}$ & $1.11 \pm 0.03^{* \#}$ \\
\hline Wall area $\left(\mathrm{mm}^{2}\right)$ & $11.04 \pm 0.81$ & $16.55 \pm 0.98^{* *}$ & $13.95 \pm 0.62^{* \#}$ & $15.51 \pm 0.92^{* *}$ \\
\hline Wet weight per unit $(\mathrm{g} / \mathrm{cm})$ & $0.13 \pm 0.02$ & $0.15 \pm 0.02^{*}$ & $0.15 \pm 0.02^{*}$ & $0.16 \pm 0.02^{*}$ \\
\hline
\end{tabular}

Compared with Con: ${ }^{*} P<0.05,{ }^{* *} P<0.01$; compared with DM: ${ }^{\#} P<0.05$.

TABLE 2: Parameters of biomechanical properties of colon.

\begin{tabular}{lcccc}
\hline & Con & DM & T1 & T2 \\
\hline Opening angle (degree) & $101.45 \pm 8.84$ & $223.66 \pm 21.93^{* *}$ & $159.17 \pm 12.31^{* \#}$ & $195.341 \pm 17.22^{*}$ \\
Inner residual strain (unitless) & $-0.21 \pm 0.02$ & $-0.29 \pm 0.03^{*}$ & $-0.26 \pm 0.02^{*}$ & $-0.27 \pm 0.03^{*}$ \\
Outer residual strain (unitless) & $0.12 \pm 0.02$ & $0.22 \pm 0.03^{* *}$ & $0.12 \pm 0.01^{\# \#}$ & $0.26 \pm 0.03^{* *}$ \\
Circumferential constant $\alpha(\mathrm{kPa})$ & $1.13 \pm 0.16$ & $2.12 \pm 0.28^{* *}$ & $1.87 \pm 0.3162^{* \#}$ & $2.61 \pm 0.38^{* *}$ \\
Longitudinal constant $\alpha(\mathrm{kPa})$ & $25.48 \pm 4.12$ & $52.34 \pm 8.73^{* *}$ & $36.13 \pm 2.48^{* \#}$ & $44.76 \pm 5.59^{* *}$ \\
\hline
\end{tabular}

Compared with Con: ${ }^{*} P<0.05,{ }^{* *} P<0.01$; compared with DM: ${ }^{\#} P<0.05,{ }^{\# \#} P<0.01$.

of residual strain $(P<0.05)$. Computation of constant $\alpha$ showed a significant difference between the DM group and the Con group $(P<0.05)$. High-dosage CRT (T1) treatment significantly decreased the stiffness of the colonic wall in both circumferential $(P<0.05)$ and longitudinal $(P<0.05)$ directions. Low-dosage CRT treatment (T2) did not show improvement in the stiffening of the colonic wall caused by diabetes $(P>0.05)$.

3.3. Fractions of AGE, RAGE, TGF- $\beta 1$, and TGF- $\beta 1$ Receptor Expressions in Different Groups. The fraction of AGE, RAGE, TGF- $\beta 1$, and TGF- $\beta 1$ receptor expressions in the different layers of the colon in different groups were shown in Table 3. The representative samples of immunohistochemical staining were shown in Figure 1. Generally the expression of all proteins was stronger in the muscle layer than other layers. The expressions of AGE, RAGE, TGF- $\beta 1$, and TGF$\beta 1$ receptor in different layers were upregulated in the DM group than in Con group. Treatment with a high dosage of CRT (T1 group) partially reversed the abnormal expressions of different proteins in the different layers of the colon wall; however they did not significantly change in the T2 group. The detail results including $P$ values were shown in Table 3.

\subsection{Correlation Analysis Results}

3.4.1. Single Linear Correlation Analysis. In order to analyze the expressions of AGE, RAGE, TGF- $\beta 1$, and TGF- $\beta 1$ receptor with other parameters, the linear regression analysis was separately done on the expressions of AGE, RAGE, TGF$\beta 1$, and TGF- $\beta 1$ receptor in different layers of the colon wall with blood glucose level, body weight, wet weight per unit length of the colon, wall thickness, wall cross-sectional area, opening angle, inner residual strain, outer residual strain, circumferential material constant $\alpha$, and longitudinal material constant $\alpha$. It was shown that expressions of AGE, RAGE, and TGF- $\beta 1$ receptor correlated with most of the other parameters. Table 4 listed some results of the correlation. AGE and RAGE in different layers were highly correlated with glucose level, wall thickness, wall area, opening angle, and outer residual strain. AGE and RAGE in muscle layer correlated with circumferential material constant $\alpha$, whereas RAGE in muscle and submucosa layers correlated with longitudinal material constant $\alpha$. TGF- $\beta 1$ receptor in different layers correlated with most parameters, whereas it was only found that the TGF- $\beta 1$ in muscle layer correlated with glucose level, body weight, and circumferential and longitudinal material constant $\alpha$. The details of correlation equations and values of $R$ and $P$ were shown in Table 4 .

3.4.2. Multiple Linear Correlation Analysis. In order to determine the main contributor of AGE, RAGE, TGF- $\beta 1$, and TGF- $\beta 1$ receptor expressions in different layers in association with other parameters, and to see interrelation among AGE, RAGE, TGF- $\beta 1$, and TGF- $\beta 1$ receptor expressions, the multiple linear correlation analysis was done.

Table 5 showed the relation between some parameters with the expressions of AGE, RAGE, TGF- $\beta 1$, and TGF$\beta 1$ receptor in different layers. Glucose level and wall area mainly correlated with AGE and RAGE expressions. Outer residual strain correlated with all proteins expressions in the mucosa layer and with RAGE expressions in the muscle and submucosa layers. Opening angle was mainly determined by the RAGE in mucosa layer, AGE in muscle layer, and TGF$\beta 1$ receptor in muscle and submucosa layers. Circumferential material constant $\alpha$ seems more related to TGF- $\beta 1$ in mucosa and AGE in muscle and submucosa layers, whereas longitudinal constant $\alpha$ seems more related to AGE in mucosa, TGF$\beta 1$ in muscle, and RAGE in submucosa layers. The details of correlation equations and values of $R, F$, and $P$ were shown in Table 5.

Interrelation among AGE, RAGE, TGF- $\beta 1$, and TGF$\beta 1$ receptor expressions in different layers was shown in Table 6. AGE and TGF- $\beta 1$ in different layers mostly correlated 
TABLE 3: Fractions of AGE, RAGE, TGF- $\beta 1$, and TGF- $\beta 1$ receptor expressions.

\begin{tabular}{lccccc}
\hline Proteins & Layers & Con & DM & T1 & T2 \\
\hline \multirow{3}{*}{ AGE } & Mucosa & $0.135 \pm 0.027$ & $0.196 \pm 0.028^{*}$ & $0.085 \pm 0.019^{\# \#}$ & $0.138 \pm 0.029^{\#}$ \\
& Muscle & $0.147 \pm 0.040$ & $0.474 \pm 0.065^{* *}$ & $0.173 \pm 0.069^{\# \#}$ & $0.452 \pm 0.099^{* *}$ \\
& Submucosa & $0.032 \pm 0.011$ & $0.167 \pm 0.035^{* *}$ & $0.049 \pm 0.012^{\# \#}$ & $0.094 \pm 0.012^{* \#}$ \\
RAGE & Mucosa & $0.054 \pm 0.007$ & $0.113 \pm 0.040^{* *}$ & $0.052 \pm 0.017^{\# \#}$ & $0.150 \pm 0.041^{* *}$ \\
& Muscle & $0.189 \pm 0.061$ & $0.378 \pm 0.093^{* *}$ & $0.162 \pm 0.042^{\# \#}$ & $0.423 \pm 0.087^{* *}$ \\
& Submucosa & $0.059 \pm 0.033$ & $0.263 \pm 0.078^{* *}$ & $0.071 \pm 0.021^{\# \#}$ & $0.226 \pm 0.047^{*}$ \\
TGF- $\beta 1$ & Mucosa & $0.061 \pm 0.014$ & $0.119 \pm 0.036^{* *}$ & $0.065 \pm 0.012^{\# \#}$ & $0.194 \pm 0.062^{* *}$ \\
& Muscle & $0.211 \pm 0.028$ & $0.331 \pm 0.072^{*}$ & $0.191 \pm 0.031^{\#}$ & $0.344 \pm 0.102^{*}$ \\
& Submucosa & $0.097 \pm 0.019$ & $0.173 \pm 0.051^{* *}$ & $0.099 \pm 0.022^{\# \#}$ & $0.275 \pm 0.083^{* *}$ \\
TGF- $\beta 1$ receptor & Mucosa & $0.116 \pm 0.025$ & $0.232 \pm 0.066^{* *}$ & $0.141 \pm 0.024^{\#}$ & $0.278 \pm 0.035^{* *}$ \\
& Muscle & $0.188 \pm 0.008$ & $0.422 \pm 0.079^{* *}$ & $0.227 \pm 0.022^{\# \#}$ & $0.403 \pm 0.044^{* *}$ \\
& Submucosa & $0.231 \pm 0.023$ & $0.379 \pm 0.069^{*}$ & $0.222 \pm 0.017^{\#}$ & $0.399 \pm 0.021^{*}$ \\
\hline
\end{tabular}

Compared with Con: ${ }^{*} P<0.05,{ }^{* *} P<0.01$; compared with DM: ${ }^{\#} P<0.05,{ }^{\# \#} P<0.01$.
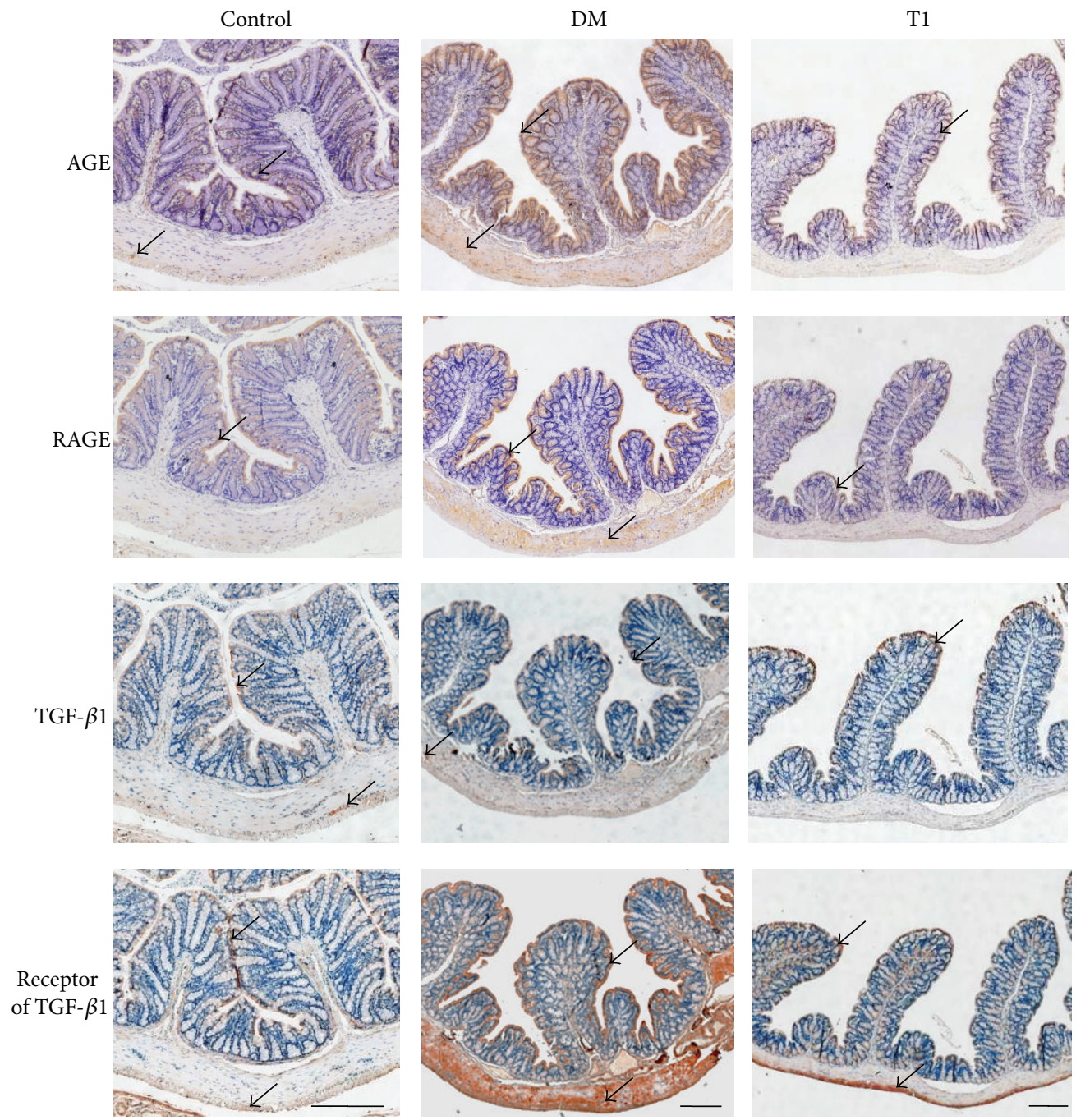

$\mathrm{T} 2$
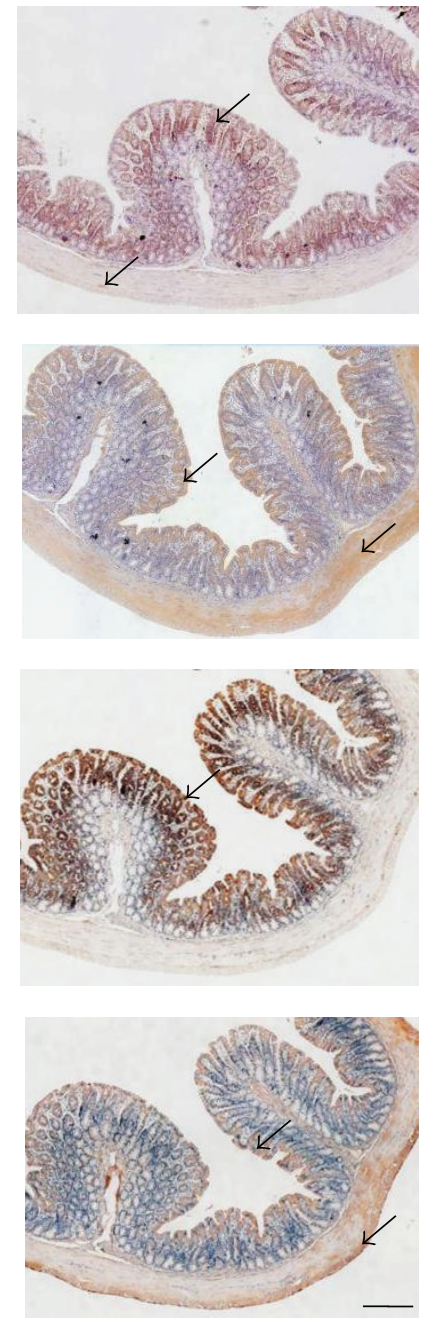

FIGURE 1: The representative samples of immunohistochemical staining for AGE, RAGE, TGF- $\beta 1$, and TGF- $\beta 1$ receptor in different groups. The brown color indicated positive staining and the arrows were to point the examples where the immunostaining is positive. The staining of all proteins was stronger in the muscle layer than other layers. The staining of AGE, RAGE, TGF- $\beta 1$, and TGF- $\beta 1$ receptor in different layers was stronger in the DM group than in Con group. Treatment with a high dosage of CRT (T1 group) partially reversed the abnormal expressions of different proteins in the different layers of the colon wall; however they did not significantly change in the T2 group. Bar $=$ $1 \mathrm{~mm}$. 
TABLE 4: The relation between expressions of AGE, RAGE TGF- $\beta 1$, and TGF- $\beta 1$ receptor with other parameters.

\begin{tabular}{|c|c|c|c|}
\hline Proteins & Linear regression equation & $R$ values & $P$ values \\
\hline \multirow[t]{18}{*}{ AGE } & AGE-M $=0.0651+(0.00311 *$ Glu $)$ & 0.527 & 0.010 \\
\hline & AGE-M $=-0.0297+(0.0115 * \mathrm{~W}-\mathrm{a})$ & 0.553 & 0.006 \\
\hline & AGE-M $=0.0690+(0.375 *$ Res-out $)$ & 0.576 & 0.004 \\
\hline & AGE-M $=0.0472+(0.000549 * \mathrm{OA})$ & 0.536 & 0.008 \\
\hline & $\mathrm{AGE}-\mathrm{Mu}=0.0367+(0.0134 * \mathrm{Glu})$ & 0.673 & $<0.001$ \\
\hline & $\mathrm{AGE}-\mathrm{Mu}=-0.540+(0.802 * \mathrm{~W}-\mathrm{h})$ & 0.479 & 0.021 \\
\hline & $\mathrm{AGE}-\mathrm{Mu}=-0.304+(0.0450 * \mathrm{~W}-\mathrm{a})$ & 0.640 & 0.001 \\
\hline & AGE-Mu $=0.0765+(1.494 *$ Res-out $)$ & 0.679 & $<0.001$ \\
\hline & $\mathrm{AGE}-\mathrm{Mu}=-0.0104+(0.00219 * \mathrm{OA})$ & 0.632 & 0.001 \\
\hline & $\mathrm{AGE}-\mathrm{Mu}=0.167+(0.0910 * \mathrm{C}-\alpha)$ & 0.430 & 0.040 \\
\hline & AGE-Sub $=0.00190+(0.00426 *$ Glu $)$ & 0.636 & 0.001 \\
\hline & AGE-Sub $=0.223-(0.000435 * \mathrm{BW})$ & 0.498 & 0.015 \\
\hline & AGE-Sub $=0.00176+(168.500 * \mathrm{Wt})$ & 0.462 & 0.026 \\
\hline & AGE-Sub $=-0.267+(0.332 * \mathrm{~W}-\mathrm{h})$ & 0.590 & 0.003 \\
\hline & AGE-Sub $=-0.121+(0.0153 * \mathrm{~W}-\mathrm{a})$ & 0.648 & $<0.001$ \\
\hline & AGE-Sub $=0.00494+(0.526 *$ Res-out $)$ & 0.711 & $<0.001$ \\
\hline & AGE-Sub $=-0.0129+(0.000694 * \mathrm{OA})$ & 0.596 & 0.003 \\
\hline & AGE-Sub $=0.0254+(0.0376 * \mathrm{C}-\alpha)$ & 0.529 & 0.009 \\
\hline \multirow[t]{20}{*}{ RAGE } & RAGE-M $=0.0114+(0.00418 *$ Glu $)$ & 0.544 & 0.007 \\
\hline & RAGE-M $=0.229-(0.000415 * \mathrm{BW})$ & 0.435 & 0.038 \\
\hline & RAGE-M $=-0.00701+(201.874 * \mathrm{Wt})$ & 0.507 & 0.014 \\
\hline & RAGE-M $=-0.231+(0.310 * \mathrm{~W}-\mathrm{h})$ & 0.504 & 0.014 \\
\hline & RAGE-M $=-0.111+(0.0153 * \mathrm{~W}-\mathrm{a})$ & 0.636 & 0.001 \\
\hline & RAGE-M $=0.0507+(0.340 *$ Res-out $)$ & 0.421 & 0.046 \\
\hline & $\mathrm{RAGE}-\mathrm{M}=0.00428+(0.000625 * \mathrm{OA})$ & 0.529 & 0.009 \\
\hline & RAGE-Mu $=0.0833+(0.0107 *$ Glu $)$ & 0.565 & 0.005 \\
\hline & RAGE-Mu $=0.631-(0.00104 * \mathrm{BW})$ & 0.443 & 0.034 \\
\hline & RAGE-Mu $=-0.0898+(0.0296 * \mathrm{~W}-\mathrm{a})$ & 0.501 & 0.015 \\
\hline & RAGE-Mu $=0.0857+(0.00148 * \mathrm{OA})$ & 0.510 & 0.013 \\
\hline & $\mathrm{RAGE}-\mathrm{Mu}=0.172+(0.0826 * \mathrm{C}-\alpha)$ & 0.438 & 0.037 \\
\hline & RAGE-Mu $=0.184+(0.00456 * \mathrm{~L}-\alpha)$ & 0.416 & 0.048 \\
\hline & RAGE-Sub $=-0.0181+(0.00827 *$ Glu $)$ & 0.630 & 0.001 \\
\hline & RAGE-Sub $=0.431-(0.000889 *$ BW $)$ & 0.546 & 0.007 \\
\hline & RAGE-Sub $=-0.0568+(403.042 * \mathrm{Wt})$ & 0.593 & 0.003 \\
\hline & RAGE-Sub $=-0.547+(0.576 * \mathrm{~W}-\mathrm{h})$ & 0.549 & 0.007 \\
\hline & RAGE-Sub $=-0.194+(0.0258 * \mathrm{~W}$-a $)$ & 0.627 & 0.001 \\
\hline & RAGE-Sub $=-0.0213+(0.00117 * \mathrm{OA})$ & 0.582 & 0.004 \\
\hline & RAGE-Sub $=0.0663+(0.00336 * \mathrm{~L}-\alpha)$ & 0.441 & 0.035 \\
\hline \multirow[t]{4}{*}{ TGF- $\beta 1$} & TGF- $\beta 1-\mathrm{M}=0.0129+(0.00553 *$ Glu $)$ & 0.564 & 0.009 \\
\hline & TGF- $\beta 1-\mathrm{M}=0.285-(0.000501 * \mathrm{BW})$ & 0.431 & 0.040 \\
\hline & TGF- $\beta 1-\mathrm{M}=0.0415+(0.0489 * \mathrm{C}-\alpha)$ & 0.474 & 0.022 \\
\hline & TGF- $\beta 1-\mathrm{M}=0.0622+(0.00235 * \mathrm{~L}-\alpha)$ & 0.447 & 0.049 \\
\hline \multirow[t]{8}{*}{ TGF- $\beta 1$ receptor } & TGFR-M $=0.0894+(0.00425 *$ Glu $)$ & 0.443 & 0.034 \\
\hline & TGFR-M $=0.330-(0.000495 *$ BW $)$ & 0.435 & 0.038 \\
\hline & TGFR-M $=0.0294+(275.036 * \mathrm{Wt})$ & 0.531 & 0.009 \\
\hline & TGFR-M $=-0.197+(0.346 * \mathrm{~W}-\mathrm{h})$ & 0.447 & 0.033 \\
\hline & TGFR-M $=-0.114+(0.0208 * \mathrm{~W}-\mathrm{a})$ & 0.609 & 0.002 \\
\hline & TGFR-M $=0.0637+(0.684 *$ Res-out $)$ & 0.654 & $<0.001$ \\
\hline & TGFR-M $=0.0687+(0.000705 *$ OA $)$ & 0.431 & 0.040 \\
\hline & TGFR-Mu $=0.123+(0.00785 *$ Glu $)$ & 0.627 & 0.001 \\
\hline
\end{tabular}


TABLE 4: Continued.

\begin{tabular}{llcc}
\hline Proteins & Linear regression equation & $R$ values & $P$ values \\
\hline TGFR-Mu $=0.522-(0.000753 * \mathrm{BW})$ & 0.507 & 0.013 \\
TGFR-Mu $=0.113+(334.580 * \mathrm{Wt})$ & 0.495 & 0.593 & 0.016 \\
TGFR-Mu $=-0.0774+(0.0264 * \mathrm{~W}-\mathrm{a})$ & 0.473 & 0.003 \\
TGFR-Mu $=0.188+(0.645 *$ Res-out $)$ & 0.559 & 0.023 \\
TGFR-Mu $=0.104+(0.00119 * \mathrm{OA})$ & 0.419 & 0.006 \\
TGFR-Sub $=0.190+(0.00488 * \mathrm{Glu})$ & 0.451 & 0.047 \\
TGFR-Sub $=0.449-(0.000506 * \mathrm{BW})$ & 0.486 & 0.031 \\
TGFR-Sub $=0.160+(248.342 * \mathrm{Wt})$ & 0.473 & 0.019 \\
TGFR-Sub $=0.0479+(0.0176 * \mathrm{~W}-\mathrm{a})$ & 0.415 & 0.023 \\
TGFR-Sub $=0.208+(0.526 *$ Res-out $)$ & & 0.049 \\
TGFR-Sub $=0.185+(0.000700 *$ OA $)$ & & \\
\hline
\end{tabular}

Notes: M, mucosa; Mu, muscle; Sub, submucosa; Glu, glucose; BW, body weight; Wt, weight per unit length; W-h, wall thickness; W-a, wall area; Res-in, inner residual strain; Res-out, outer residual strain; OA, opening angle, C- $\alpha$, circumferential constant $\alpha$; L- $\alpha$, longitudinal constant $\alpha$.

with their receptors: RAGE and TGF- $\beta 1$ receptor. Similarly RAGE and TGF- $\beta 1$ receptor in different layers also correlated with AGE and TGF- $\beta 1$. However it is interesting to notice that RAGE and TGF- $\beta 1$ receptor in muscle layers were strongly correlated with each other. The details of correlation equations and values of $R, F$, and $P$ were shown in Table 6 .

\section{Discussion}

Previously we demonstrated that CRT could restore the morphometric and biomechanical remodeling of colon in streptozotocin- (STZ-) induced diabetic rats [13]. The main finding found at the present study was that the expression of AGE, RAGE, TGF- $\beta 1$, and TGF- $\beta 1$ receptor was significantly higher in different colon layers in the DM group than in Con group. The expressions of those proteins were highly correlated to the histomorphometric and biomechanical remodeling parameters. Furthermore, the expressions of AGE, RAGE, TGF- $\beta$, and TGF- $\beta$ receptor were significantly decreased in the $\mathrm{T} 1$ group but not in the $\mathrm{T} 2$ group.

4.1. Diabetes Upregulates Expressions of AGE, RAGE, TGF$\beta 1$, and TGF- $\beta 1$ Receptor in Rat Colon Wall. Diabetic GI complications are common in long-standing diabetes [24]. Poor control of diabetes can affect any segment of the gut including the colon [25]. Although many studies have demonstrated that diabetic GI complications involved multifactors [26], the mechanisms are not well understood. At present study we demonstrated that the expressions of AGE, RAGE, TGF- $\beta 1$, and TGF- $\beta 1$ receptor were upregulated in the different layers of diabetic colon wall. It indicated that the abnormal expressions of these proteins are related to diabetic GI complications.

AGEs and RAGE accumulated during the development of DM are associated with cardiovascular complication [27], retinopathy [28], and nephropathy [29] as well as GI complications [30]. Recently Chen and coworkers [31,32] have found that AGE and RAGE are upregulated in the diabetic small intestine and colon for both type 1 and type 2 diabetic animal models. The present study confirms these findings. The accumulated AGEs may affect the tissue structural changes and neuromuscular function of diabetic GI tract through receptor-dependent and receptor-independent pathways [33,34]. The former modulates cellular functions through ligation of specific cell surface receptors such as RAGE. The latter alters the extracellular matrix architecture by nonenzymatic glycation and the formation of protein cross-links.

Transforming growth factor- (TGF-) $\beta 1$ is a ubiquitously expressed cytokine belonging to a large superfamily of activins/bone morphogenetic proteins [35]. This mediator plays an active role in the processes of wound healing [36] and synthesis of ECM molecules [37]. It was reported that plasma levels of TGF- $\beta 1$ were elevated in NIDDM patients and might contribute to the occurrence of diabetic complications [38]. Indeed, many studies have demonstrated that TGF- $\beta$ strongly contributes to diabetic nephropathy $[17,18]$, diabetic retinopathy $[39,40]$, and diabetic neuropathy [41]. In the present study, we first demonstrated that the TGF- $\beta 1$ and TGF- $\beta 1$ receptor were upregulated in the diabetic colon wall. Although no detail molecular pathway was demonstrated in the present study, the increasing TGF- $\beta 1$ may through ligand binding activate TGF- $\beta 1$ receptors and then activate Smad proteins through phosphorylation according to a review article about the role of TGF- $\beta$ in gastrointestinal pathophysiology and modulation of ulcer healing [42].

Analysis for interrelation among AGE, RAGE, TGF$\beta 1$, and TGF- $\beta 1$ receptor showed that AGE and TGF- $\beta 1$ in different layers mostly correlated with their receptors: RAGE and TGF- $\beta 1$ receptor. It seems easy to understand that the effects of AGE and TGF- $\beta 1$ are through their corresponding receptors. However it is interesting to notice that RAGE and TGF- $\beta 1$ receptor in muscle layers were strongly correlated with each other. There are some studies to investigate the complicated interaction between AGE and TGF- $\beta 1$ with their receptors in the pathological progression of diabetic nephropathy [43,44] and interstitial fibrosis 


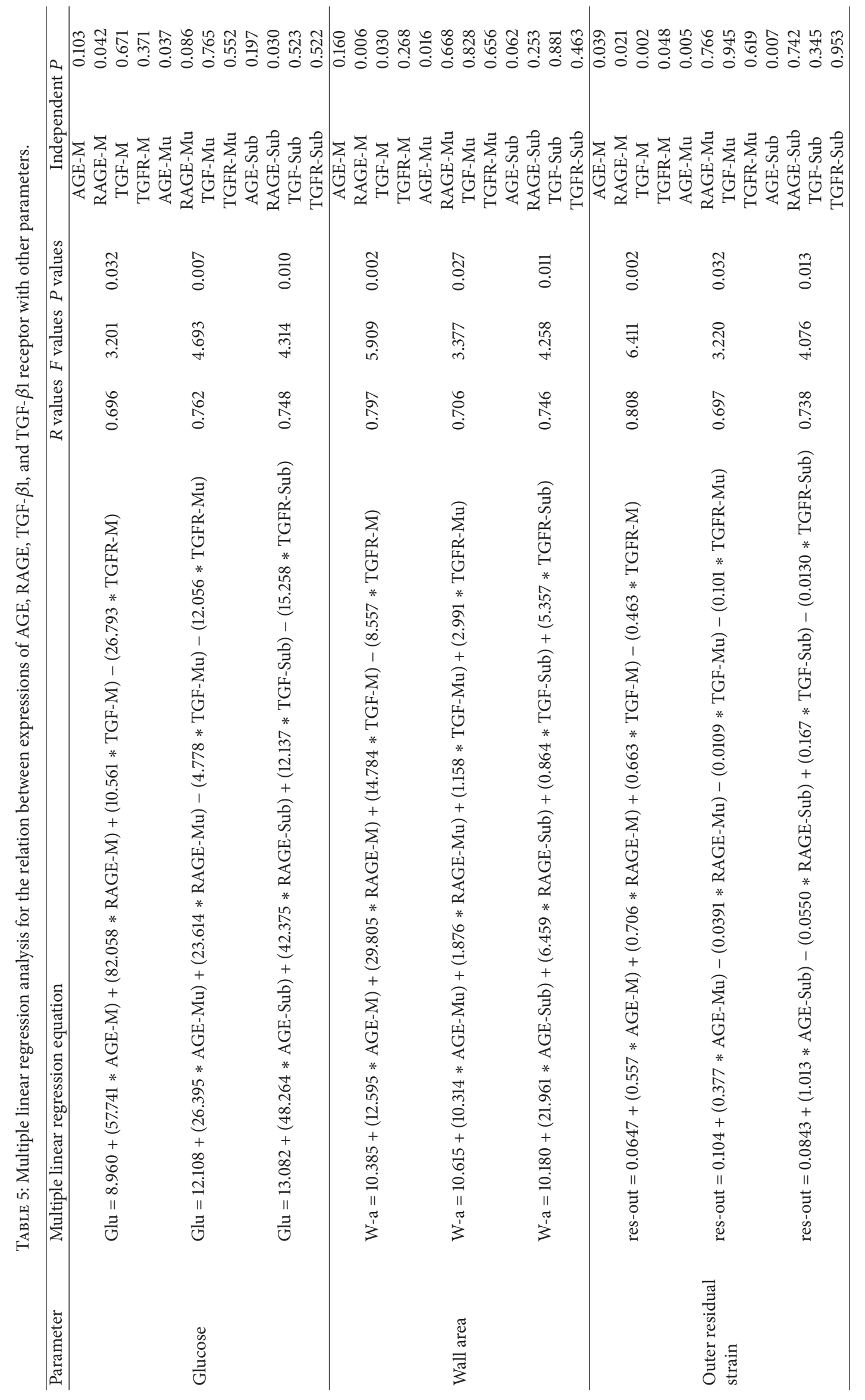




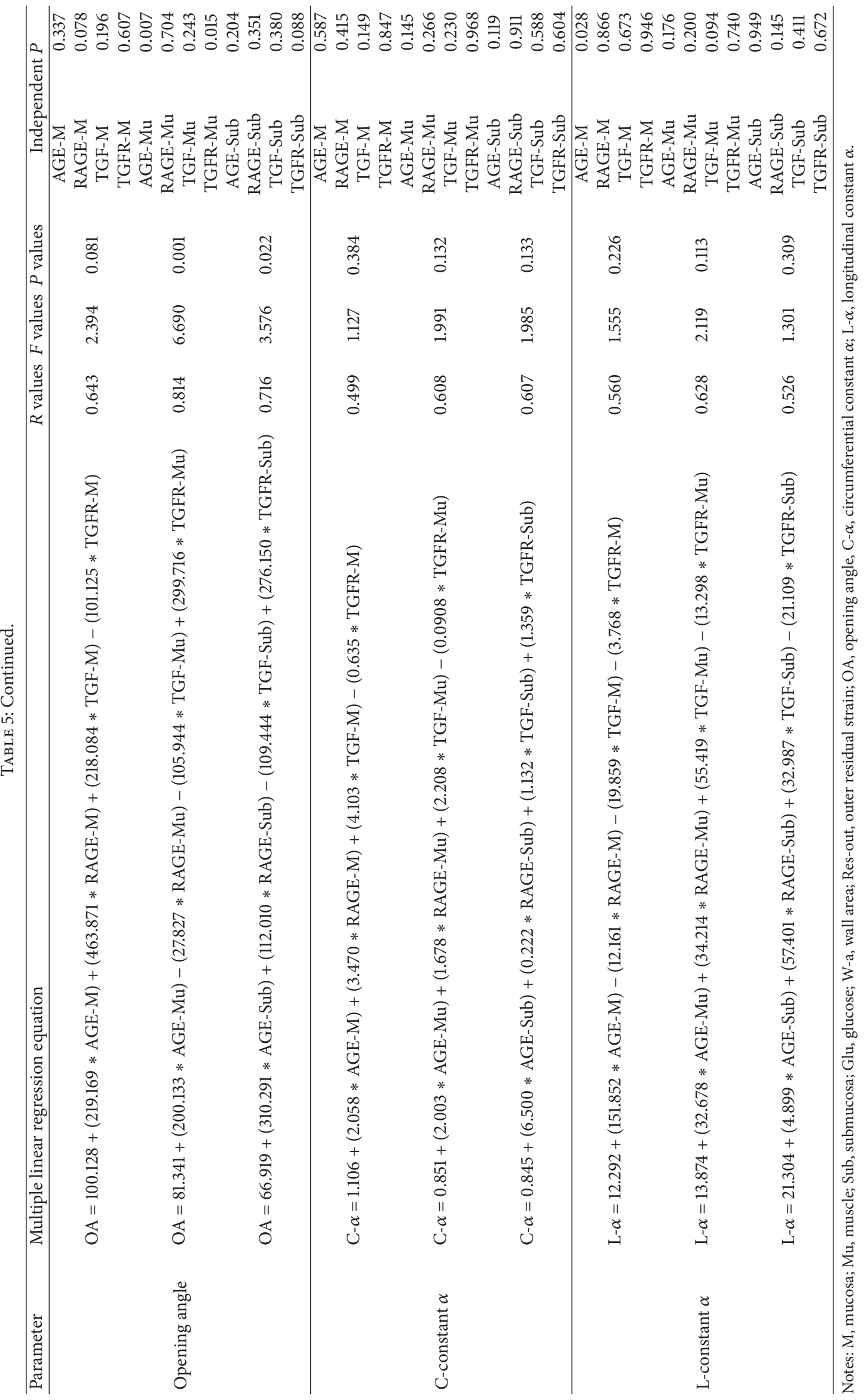




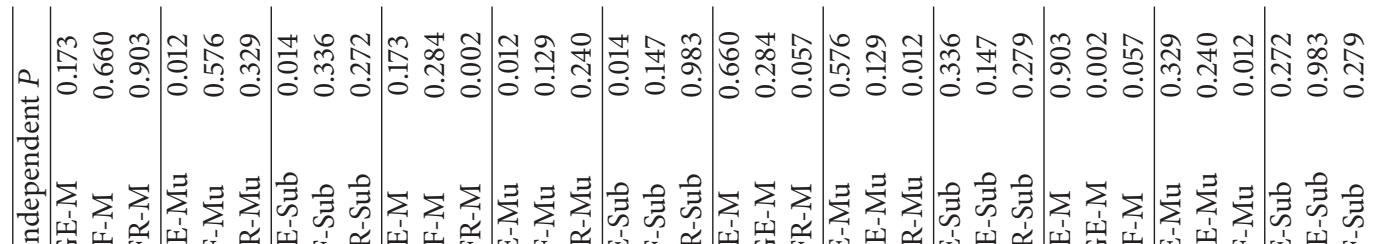

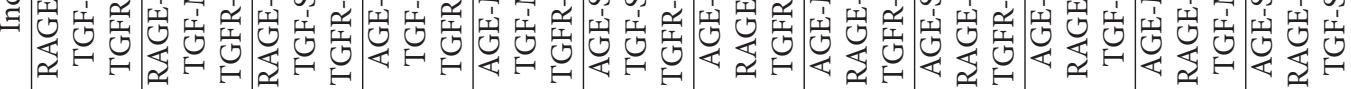

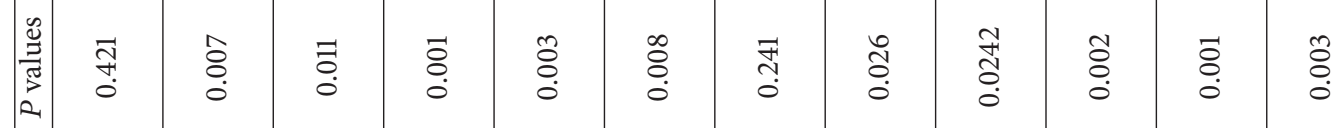

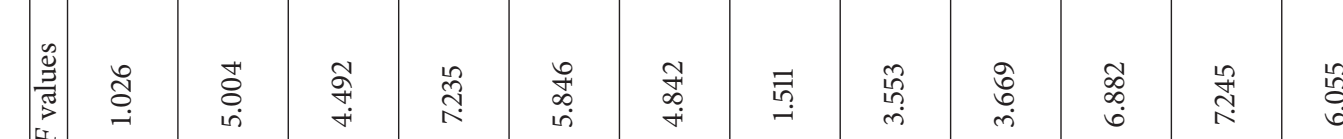

D.

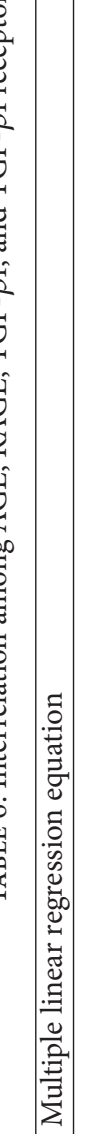

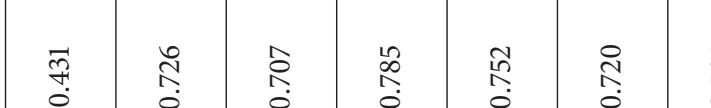

1
0
0
0

כ

$\widehat{\Sigma}$

$\sum_{i=1}^{\Xi} \underset{\sim}{\overrightarrow{1}}$

嵌

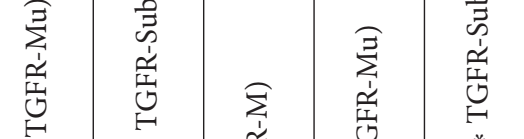

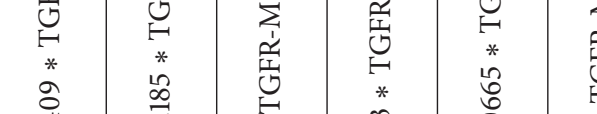

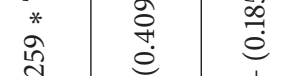

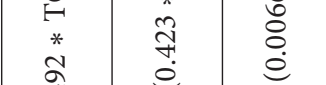

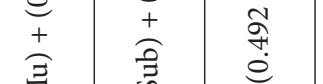

1

$\sum_{\substack{1 \\ 5}}^{3}$

站

D $\sum_{i}^{+}$

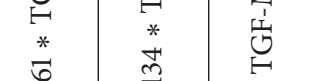

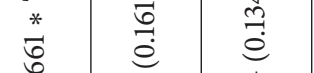

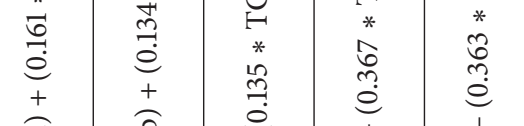

高 站

$\stackrel{+}{\sum_{1}}$

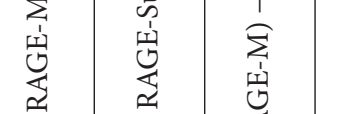

先

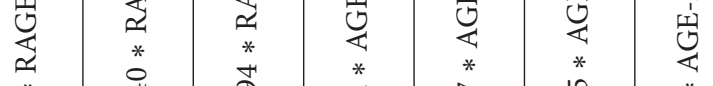

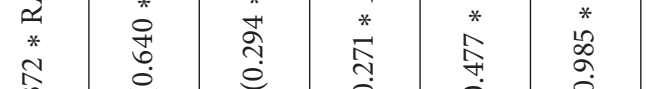

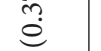

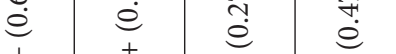

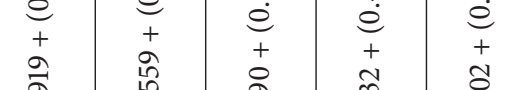

궁

o.

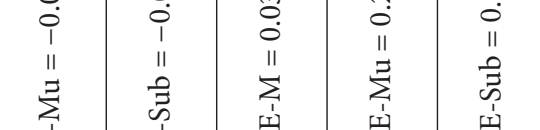

$\Sigma$

䆥

岳

望

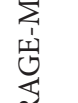

荇

(a)

$\stackrel{5}{6}$

喜

:

$\stackrel{\infty}{\stackrel{\infty}{0}}$

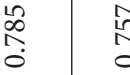

i

㭊

$*$
$*$
8
0 
induced by imbalances in extracellular matrix homeostasis [45]. However interpretation for the relation between RAGE and TGF- $\beta 1$ receptor in the diabetic GI complication is needed to explore.

4.2. Diabetes-Induced Morphological and Biomechanical Remodeling of Rat Colon Associates with the Abnormal Expressions of AGE, RAGE, TGF- $\beta 1$, and TGF- $\beta 1$ Receptor. We have previously demonstrated that the histomorphological and biomechanical remodeling occurred in the diabetic rat model [11]; that is, diabetes generated pronounced increases in the colon wall thickness, wall cross-sectional area, the thickness of all layers, the opening angle, the absolute values of residual strain, and the circumferential and longitudinal stiffness of the colon wall. However, the mechanism of such remodeling is not so clear. It was shown from the study of relation between AGEs and vascular wall stiffness that glycation-induced intermolecular cross-links contributed to diabetic vascular stiffening [46]. Evidences showed that AGE formation in arteries was associated with arterial stiffening during aging [47]. Also study found that high serum AGE concentrations are associated with increased arterial stiffness and thickness in patients with diabetes [48]. More recently one study demonstrated that chronic CML ingestion induced arterial stiffness and aging in a RAGE-dependent manner in the mice [49]. The abovementioned studies demonstrated that the morphological and biomechanical remodeling of arteries in diabetes is closely associated with AGE and RAGE. We, in a previous study [16], demonstrated that the most histomorphometric and biomechanical parameters of intestinal wall in the GK diabetic rats were associated with the expression of AGE and RAGE in villi, especially that the highest association was found between the mechanical constant $\alpha$ and villous AGE. At the same time, it was also found that the mechanical constant $\alpha$ was associated with AGE and RAGE expressions in the crypt. In the present study, we further confirmed that diabetes-induced morphological and biomechanical remodeling of rat colon were also closely associated with the abnormal expressions of AGE and RAGE in the different layers of colon wall.

Data is lacking in relation to the association between TGF- $\beta 1$ and TGF- $\beta 1$ receptor and gastrointestinal morphological and biomechanical remodeling in diabetes. Fleenor and coworkers [50] reported that arterial stiffening with ageing is associated with TGF- $\beta 1$-related changes in adventitial collagen. Few studies demonstrated that TGF- $\beta 1$ increased F-actin levels in single chondrocytes leading to stiffening of cells $[51,52]$. In the present study, we first demonstrated that TGF- $\beta 1$ in muscle layer correlated with circumferential and longitudinal material constant $\alpha$, whereas TGF- $\beta 1$ receptor in different layers correlated with most morphological and biomechanical parameters. It is also interesting to notice that RAGE and TGF- $\beta 1$ receptor in muscle layers were strongly correlated with each other. This may indicate that either TGF- $\beta 1$ is an independent contributing factor or TGF$\beta 1$ and AGE are cocontributors for the morphological and biomechanical remodeling of colon in diabetes. The detail molecular pathways for the effect of AGE and TGF- $\beta 1$ on colonic remodeling in diabetes are needed to further explore.

4.3. Corrective Effect of CRT (High Dose) on Those Proteins Expressions Is One of the Molecular Pathways for the Improvement of CRT on the Colon Remodeling in Diabetic Rats. Clinically we found that CRT decoction was very effective to treat senile constipation. Studies have shown that Herba Cistanches had laxative activity in the intestine and promoted bowel movement [53]. Semen Arecae Prepareta promoted gastrointestinal movement, excited cholinergic M receptor, and promoted spontaneous contraction of isolated ileum [54]. Fructus Aurantii Immaturus enhanced gastrointestinal smooth muscle contraction and intestinal propulsive function [55]. Fructus Cannabis could shorten the defecation time and significantly increase frequency of bowel movements [56, 57]. Radix Angelicae Sinensis could promote bowel movement [58]. Therefore, the CRT could regulate GI motility and improve the symptoms in patients with constipation. Previous study has demonstrated that the experimental diabetes could induce colon morphological and biomechanical remodeling [11]. Such remodeling plays an important role in diabetic GI complications including the constipation [12]. In order to investigate the mechanism of CRT to treat the constipation whether or not through the improvement of the morphometric and biomechanical remodeling, we selected STZ-induced diabetic rat model to test the CRT on the morphometric and colonic remodeling induced by diabetes. We have demonstrated that high-dose CRT could partly reverse the diabetes-induced morphological and biomechanical remodeling of colon [13] (Tables 1 and 2). However the mechanism of the CRT effect is not clear. In the present study we demonstrated that the expressions of AGE, RAGE, TGF- $\beta 1$, and TGF- $\beta 1$ receptor in colonic wall of STZ-induced diabetic rats were upregulated. The CRT (high dose) could significantly decrease the expressions of AGE, RAGE, TGF- $\beta 1$, and TGF- $\beta 1$ receptor in the diabetic colonic wall. Furthermore, we found that the expressions of AGE, RAGE, TGF- $\beta 1$, and TGF- $\beta 1$ receptor were associated with most morphological and biomechanical parameters of rat colon. In one previous study, we demonstrated that tangweian jianji (high dose) treatment partly restored the morphometric and biomechanical remodeling of the upper gastrointestinal tract in diabetic rats, and one mechanism was through decreasing the mRNA level of RAGE in the GI wall [59]. Therefore we believed that the corrective effect of CRT (high dose) on the expressions of AGE, RAGE, TGF$\beta$, and TGF- $\beta$ receptor is one of the molecular pathways for the improvement of CRT on the colon remodeling in diabetic rats.

Furthermore, we demonstrated that high dose of CRT could significantly decrease the blood glucose level in the diabetic rats [13]. The evidence of correlation analysis showed that the blood glucose level highly associated with the expressions of AGE and RAGE. Therefore, the effect of CRT on the colonic wall remodeling of diabetic rats is likely to be partly from lowing blood glucose level. The colonic wall remodeling in diabetes will alter the relative 
position of the mechanosensitive afferents (zero setting of the mechanosensitive afferents) and their environment [10]. Improving the colonic wall remodeling induced diabetes will improve colon sensory-motor function and further improve the symptoms of the patients in the clinic.

\section{Conclusion and Perspectives of the Study}

STZ-induced diabetes upregulated the expression of AGE, RAGE, TGF- $\beta 1$, and TGF- $\beta 1$ receptor in different colon layers of rats. CRT could reverse the abnormal expressions of AGE, RAGE, TGF- $\beta 1$, and TGF- $\beta 1$ receptor in the diabetic colon. The expressions of those proteins were highly associated with histomorphometric and biomechanical parameters of colon. The evidence showed that the corrective effect of CRT (high dose) on the expressions of AGE, RAGE, TGF- $\beta 1$, and TGF- $\beta 1$ receptor is one of the molecular pathways for the improvement of CRT on the colon remodeling in diabetic rats. In the future, the detail molecular pathways for the effect of AGE and TGF- $\beta 1$ on colonic remodeling in diabetes and the relation between RAGE and TGF- $\beta 1$ receptor in the diabetic GI complication are needed to explore.

\section{Conflict of Interests}

No potential conflict of interests relevant to this paper was reported.

\section{Authors' Contribution}

Hong Sha, Dong Zhao, and Jingbo Zhao designed and performed experiments, analyzed data, and wrote the paper. Xiaolin Tong and Hans Gregersen contributed to the discussion and reviewed the paper. Jingbo Zhao and Xiaolin Tong supervised the study. Hans Gregersen contributed to the language editing. Jingbo Zhao had full access to all the data in the study and takes responsibility for the integrity of data and the accuracy of data analysis.

\section{Acknowledgments}

The study was financially supported by National Key Basic Research Program of China (973), no. 2010CB530600, and Karen Elise Jensen foundation (Project no. 903959).

\section{References}

[1] J. Belsey, S. Greenfield, D. Candy, and M. Geraint, "Systematic review: impact of constipation on quality of life in adults and children," Alimentary Pharmacology \& Therapeutics, vol. 31, no. 9, pp. 938-949, 2010.

[2] S. M. Mugie, M. A. Benninga, and C. Di Lorenzo, "Epidemiology of constipation in children and adults: a systematic review," Best Practice \& Research: Clinical Gastroenterology, vol. 25, no. 1, pp. 3-18, 2011.

[3] S. M. Scott, M. M. van den Berg, and M. A. Benninga, "Rectal sensorimotor dysfunction in constipation," Best Practice \& Research: Clinical Gastroenterology, vol. 25, no. 1, pp. 103-118, 2011.
[4] R. E. Burgell, C. Bhan, P. J. Lunniss, and S. M. Scott, "Fecal incontinence in men: coexistent constipation and impact of rectal hyposensitivity," Diseases of the Colon and Rectum, vol. 55, no. 1, pp. 18-25, 2012.

[5] G. L. McCrea, C. Miaskowski, N. A. Stotts, L. Macera, and M. G. Varma, "Pathophysiology of constipation in the older adult," World Journal of Gastroenterology, vol. 14, no. 17, pp. 2631-2638, 2008.

[6] I. J. Cook, N. J. Talley, M. A. Benninga, S. S. Rao, and S. M. Scott, "Chronic constipation: overview and challenges," Neurogastroenterology \& Motility, vol. 21, no. 2, pp. 1-8, 2009.

[7] J. Tack, "Current and future therapies for chronic constipation," Best Practice \& Research: Clinical Gastroenterology, vol. 25, no. 1, pp. 151-158, 2011.

[8] S. Thayalasekeran, H. Ali, and H.-H. Tsai, "Novel therapies for constipation," World Journal of Gastroenterology, vol. 19, no. 45, pp. 8247-8251, 2013.

[9] L.-W. Lin, Y.-T. Fu, T. Dunning et al., "Efficacy of traditional Chinese medicine for the management of constipation: a systematic review," Journal of Alternative and Complementary Medicine, vol. 15, no. 12, pp. 1335-1346, 2009.

[10] H. Gregersen, Biomechanics of the Gastrointestinal Tract, Springer, London, UK, 2002.

[11] J. Zhao, T. Nakaguchi, and H. Gregersen, "Biomechanical and histomorphometric colon remodelling in STZ-Induced diabetic rats," Digestive Diseases and Sciences, vol. 54, no. 8, pp. 1636$1642,2009$.

[12] J. Zhao, D. Liao, J. Yang, and H. Gregersen, "Biomechanical remodelling of the diabetic gastrointestinal tract," in Biomechanics: Principles, Trends and Applications, J. H. Levy, Ed., pp. 137-162, Nova Publishers, 2010.

[13] H. Sha, D. Zhao, J. Zhao et al., "Effect of chang run tong on the biomechanical and morphometric remodeling of colon and rectum in streptozotocin-induced diabetic rats," Journal of Medical and Biological Engineering, vol. 33, no. 2, pp. 149-154, 2013.

[14] J. D. Méndez, J. Xie, M. Aguilar-Hernández, and V. MéndezValenzuela, "Trends in advanced glycation end products research in diabetes mellitus and its complications," Molecular and Cellular Biochemistry, vol. 341, no. 1-2, pp. 33-41, 2010.

[15] R. Ramasamy, S. F. Yan, and A. M. Schmidt, "Receptor for AGE (RAGE): signaling mechanisms in the pathogenesis of diabetes and its complications," Annals of the New York Academy of Sciences, vol. 1243, no. 1, pp. 88-102, 2011.

[16] J. Zhao, P. Chen, and H. Gregersen, "Morpho-mechanical intestinal remodeling in type 2 diabetic GK rats-is it related to advanced glycation end product formation?" Journal of Biomechanics, vol. 46, no. 6, pp. 1128-1134, 2013.

[17] S. Goldfarb and F. N. Ziyadeh, "TGF-beta: a crucial component of the pathogenesis of diabetic nephropathy," Transactions of the American Clinical and Climatological Association, vol. 112, pp. 27-33, 2001.

[18] T. Pantsulaia, "Role of TGF-beta in pathogenesis of diabetic nephropathy," Georgian Medical News, vol. 131, pp. 13-18, 2006.

[19] D. Kajdaniuk, B. Marek, H. Borgiel-Marek, and B. Kos-Kudła, "Transforming growth factor $\beta 1$ (TGF $\beta 1$ ) in physiology and pathology," Endokrynologia Polska, vol. 64, no. 5, pp. 384-396, 2013.

[20] L. Liu, J. Jiao, Y. Wang et al., “TGF-betal gene polymorphism in association with diabetic retinopathy susceptibility: a systematic review and meta-analysis," PLoS ONE, vol. 9, no. 4, Article ID e94160, 2014. 
[21] J. H. Li, X. R. Huang, H.-J. Zhu et al., "Advanced glycation end products activate Smad signaling via TGF-beta-dependent and independent mechanisms: implications for diabetic renal and vascular disease," The FASEB Journal, vol. 18, no. 1, pp. 176-178, 2004.

[22] Y. S. Kim, D. H. Jung, I. S. Lee et al., "Effects of Allium victorialis leaf extracts and its single compounds on aldose reductase, advanced glycation end products and TGF- $\beta 1$ expression in mesangial cells," BMC Complementary and Alternative Medicine, vol. 13, article 251, 2013.

[23] R. Wada and S. Yagihashi, "Role of advanced glycation end products and their receptors in development of diabetic neuropathy," Annals of the New York Academy of Sciences, vol. 1043, pp. 598-604, 2005.

[24] B. Krishnan, S. Babu, J. Walker, A. B. Walker, and J. M. Pappachan, "Gastrointestinal complications of diabetes mellitus," World Journal of Diabetes, vol. 4, no. 3, pp. 51-63, 2013.

[25] A. Shakil, R. J. Church, and S. S. Rao, "Gastrointestinal complications of diabetes," American Family Physician, vol. 77, no. 12, pp. 1697-1704, 2008.

[26] J. H. Sellin and E. B. Chang, "Therapy insight: gastrointestinal complications of diabetes-pathophysiology and management," Nature Clinical Practice Gastroenterology \& Hepatology, vol. 5, no. 3, pp. 162-171, 2008.

[27] M. Peppa and S. A. Raptis, "Advanced glycation end products and cardiovascular disease," Current Diabetes Reviews, vol. 4, no. 2, pp. 92-100, 2008.

[28] T. Sugiyama, T. Okuno, M. Fukuhara et al., "Angiotensin II receptor blocker inhibits abnormal accumulation of advanced glycation end products and retinal damage in a rat model of type 2 diabetes," Experimental Eye Research, vol. 85, no. 3, pp. 406-412, 2007.

[29] K. Fukami, S.-I. Yamagishi, S. Ueda, and S. Okuda, "Role of AGEs in diabetic nephropathy," Current Pharmaceutical Design, vol. 14, no. 10, pp. 946-952, 2008.

[30] V. M. Bhor and S. Sivakami, "Regional variations in intestinal brush border membrane fluidity and function during diabetes and the role of oxidative stress and non-enzymatic glycation," Molecular and Cellular Biochemistry, vol. 252, no. 1-2, pp. 125132, 2003.

[31] P. Chen, J. Zhao, and H. Gregersen, "Up-regulated expression of advanced glycation end-products and their receptor in the small intestine and colon of diabetic rats," Digestive Diseases and Sciences, vol. 57, no. 1, pp. 48-57, 2012.

[32] P.-M. Chen, H. Gregersen, and J.-B. Zhao, "Advanced glycation end-product expression is upregulated in the gastrointestinal tract of type 2 diabetic rats," World Journal of Diabetes, vol. 6, no. 4, pp. 662-672, 2015.

[33] A. Bierhaus, P. M. Humpert, M. Morcos et al., "Understanding RAGE, the receptor for advanced glycation end products," Journal of Molecular Medicine, vol. 83, no. 11, pp. 876-886, 2005.

[34] D. M. Stern, S. D. Yan, S. F. Yan, and A. M. Schmidt, "Receptor for advanced glycation endproducts (RAGE) and the complications of diabetes," Ageing Research Reviews, vol. 1, no. 1, pp. 1-15, 2002.

[35] Y. Shi and J. Massagué, "Mechanisms of TGF-beta signaling from cell membrane to the nucleus," Cell, vol. 113, no. 6, pp. 685$700,2003$.

[36] B. J. Faler, R. A. Macsata, D. Plummer, L. Mishra, and A. N. Sidawy, "Transforming growth factor-beta and wound healing," Perspectives in Vascular Surgery and Endovascular Therapy, vol. 18, no. 1, pp. 55-62, 2006.
[37] B. A. Hocevar and P. H. Howe, "Analysis of TGF-beta-mediated synthesis of extracellular matrix components," Methods in Molecular Biology, vol. 142, pp. 55-65, 2000.

[38] A. Pfeiffer, K. Middelberg-Bisping, C. Drewes, and H. Schatz, "Elevated plasma levels of transforming growth factor-beta 1 in NIDDM," Diabetes Care, vol. 19, no. 10, pp. 1113-1117, 1996.

[39] C. Gerhardinger, Z. Dagher, P. Sebastiani, S. P. Yong, and M. Lorenzi, "The transforming growth factor-beta pathway is a common target of drugs that prevent experimental diabetic retinopathy," Diabetes, vol. 58, no. 7, pp. 1659-1667, 2009.

[40] S. K. Paine, A. Basu, L. K. Mondal et al., "Association of vascular endothelial growth factor, transforming growth factor beta, and interferon gamma gene polymorphisms with proliferative diabetic retinopathy in patients with type 2 diabetes," Molecular Vision, vol. 18, pp. 2749-2757, 2012.

[41] M. Anjaneyulu, A. Berent-Spillson, T. Inoue, J. Choi, K. Cherian, and J. W. Russell, "Transforming growth factor- $\beta$ induces cellular injury in experimental diabetic neuropathy," Experimental Neurology, vol. 211, no. 2, pp. 469-479, 2008.

[42] T. Tanigawa, R. Pai, T. Arakawa, K. Higuchi, and A. S. Tarnawski, "TGF-beta signaling pathway: its role in gastrointestinal pathophysiology and modulation of ulcer healing," Journal of Physiology and Pharmacology, vol. 56, no. 1, pp. 3-13, 2005.

[43] M. F. Brizzi, P. Dentelli, A. Rosso et al., "RAGE- and TGF- $\beta$ receptor-mediated signals converge on STAT5 and p21waf to control cell-cycle progression of mesangial cells: a possible role in the development and progression of diabetic nephropathy," The FASEB Journal, vol. 18, no. 11, pp. 1249-1251, 2004.

[44] K.-P. Huang, C. Chen, J. Hao, J.-Y. Huang, P.-Q. Liu, and H.Q. Huang, "AGEs-RAGE system down-regulates Sirtl through the ubiquitin-proteasome pathway to promote FN and TGF- $\beta 1$ expression in male rat glomerular mesangial cells," Endocrinology, vol. 156, no. 1, pp. 268-279, 2015.

[45] A. I. Serban, L. Stanca, O. I. Geicu, M. C. Munteanu, M. Costache, and A. Dinischiotu, "Extracellular matrix is modulated in advanced glycation end products milieu via a RAGE receptor dependent pathway boosted by transforming growth factor- $\beta 1$ RAGE," Journal of Diabetes, vol. 7, no. 1, pp. 114-124, 2015.

[46] T. J. Sims, L. M. Rasmussen, H. Oxlund, and A. J. Bailey, "The role of glycation cross-links in diabetic vascular stiffening," Diabetologia, vol. 39, no. 8, pp. 946-951, 1996.

[47] D. R. Sell and V. M. Monnier, "Molecular basis of arterial stiffening: role of glycation-a mini-review," Gerontology, vol. 58, no. 3, pp. 227-237, 2012.

[48] N. Yoshida, K.-I. Okumura, and Y. Aso, "High serum pentosidine concentrations are associated with increased arterial stiffness and thickness in patients with type 2 diabetes," Metabolism: Clinical and Experimental, vol. 54, no. 3, pp. 345-350, 2005.

[49] N. Grossin, F. Auger, C. Niquet-Leridon et al., "Dietary CMLenriched protein induces functional arterial aging in a RAGEdependent manner in mice," Molecular Nutrition \& Food Research, vol. 59, no. 5, pp. 927-938, 2015.

[50] B. S. Fleenor, K. D. Marshall, J. R. Durrant, L. A. Lesniewski, and D. R. Seals, "Arterial stiffening with ageing is associated with transforming growth factor- $\beta 1$-related changes in adventitial collagen: reversal by aerobic exercise," The Journal of Physiology, vol. 588, no. 20, pp. 3971-3982, 2010.

[51] N. D. Leipzig, S. V. Eleswarapu, and K. A. Athanasiou, "The effects of TGF-betal and IGF-I on the biomechanics and cytoskeleton of single chondrocytes," Osteoarthritis and Cartilage, vol. 14, no. 12, pp. 1227-1236, 2006. 
[52] E. J. Koay, G. Ofek, and K. A. Athanasiou, "Effects of TGF$\beta 1$ and IGF-I on the compressibility, biomechanics, and straindependent recovery behavior of single chondrocytes," Journal of Biomechanics, vol. 41, no. 5, pp. 1044-1052, 2008.

[53] Y. Jia, Q. Guan, Y. Guo, and C. Du, "Echinacoside stimulates cell proliferation and prevents cell apoptosis in intestinal epithelial MODE-K cells by up-regulation of transforming growth factor$\beta 1$ expression," Journal of Pharmacological Sciences, vol. 118, no. 1, pp. 99-108, 2012.

[54] X. L. Shen and L. L. Duan, "Research on chemical composition and pharmacological of Arecae," Journal of Yichun College, vol. 31, pp. 95-97, 2009 (Chinese).

[55] D. X. Li, J. H. Ling, Y. J. Wang et al., "Effect of drugcontaining serum of immature bitter orange on cell contraction, intracellular $\mathrm{Ca} 2+$ concentration and calmodulin expression in rat antral smooth muscle cells," Shijie Huaren Xiaohua Zazhi, vol. 23, pp. 1224-1230, 2015 (Chinese).

[56] Y. X. Yi, H. Z. Wu, and Q. Wei, "Research progress of the hemp seed," Chinese Journal of Information on Traditional Chinese Medicine, vol. 10, pp. 92-94, 2003 (Chinese).

[57] C.-W. Cheng, Z.-X. Bian, L.-X. Zhu, J. C. Y. Wu, and J. J. Y. Sung, "Efficacy of a Chinese herbal proprietary medicine (Hemp Seed Pill) for functional constipation," The American Journal of Gastroenterology, vol. 106, no. 1, pp. 120-129, 2011.

[58] Q. J. Long, G. T. Wu, and S. Q. Zhu, "Research on Youdanggui's effect looseing the bowel to relieve constipation before and after processing drugs," Journal of Gansu College of Traditional Chinese Medicine, vol. 1, pp. 51-53, 2006 (Chinese).

[59] G.-F. Liu, J.-B. Zhao, Z. Zhen et al., "Effect of Tangweian Jianji on upper gastrointestinal remodeling in streptozotocin-induced diabetic rats," World Journal of Gastroenterology, vol. 18, no. 35, pp. 4875-4884, 2012. 


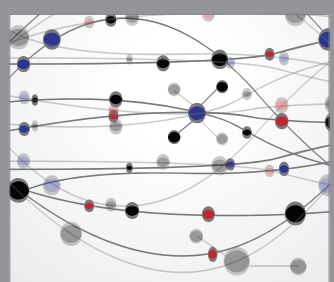

The Scientific World Journal
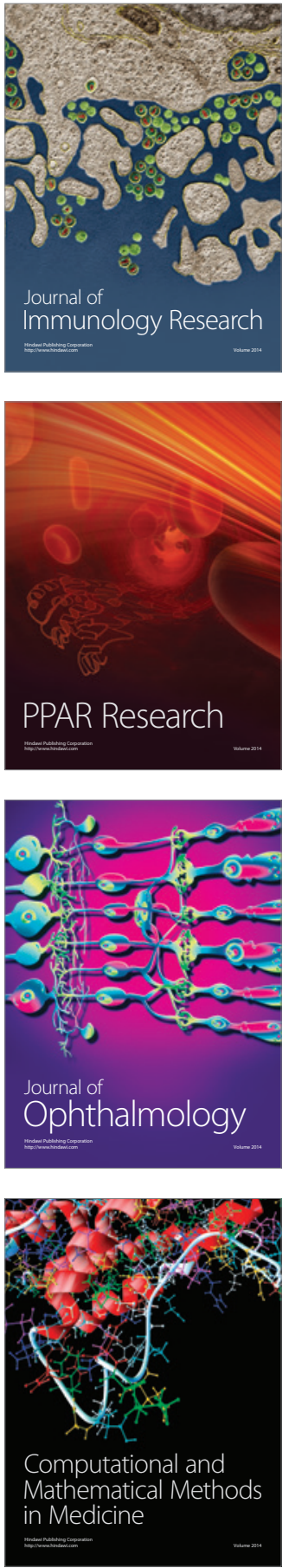

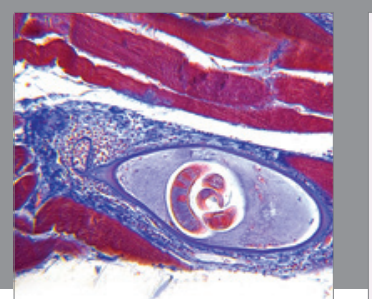

Gastroenterology Research and Practice

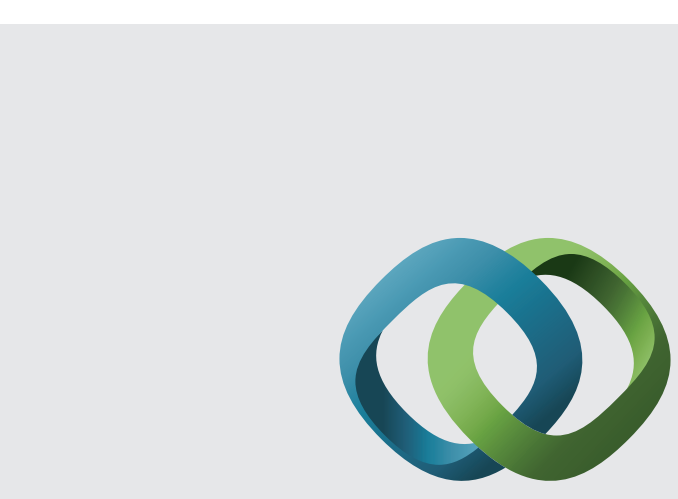

\section{Hindawi}

Submit your manuscripts at

http://www.hindawi.com
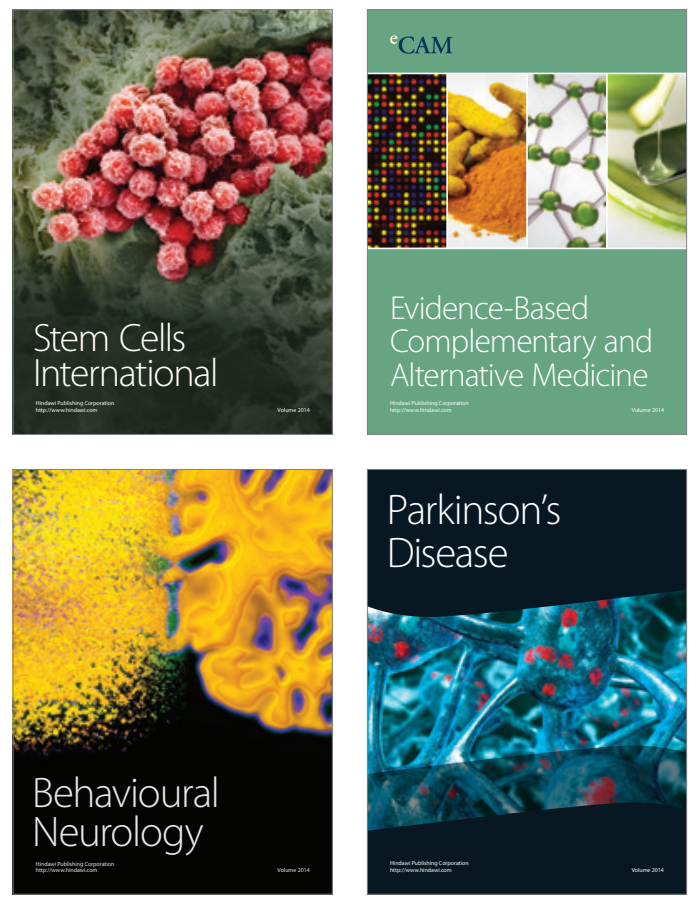
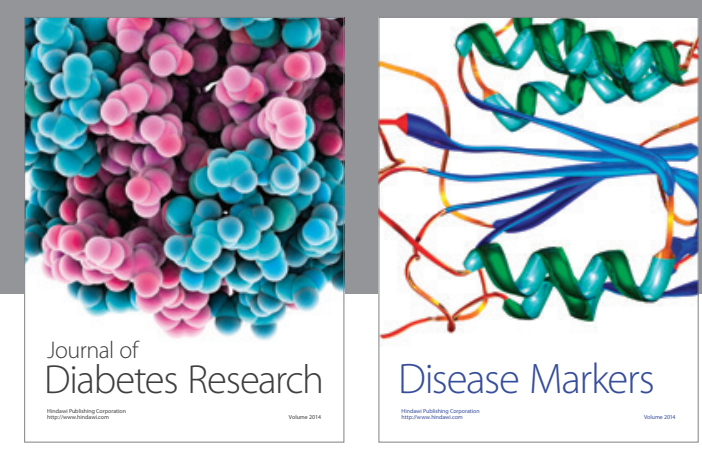

Disease Markers
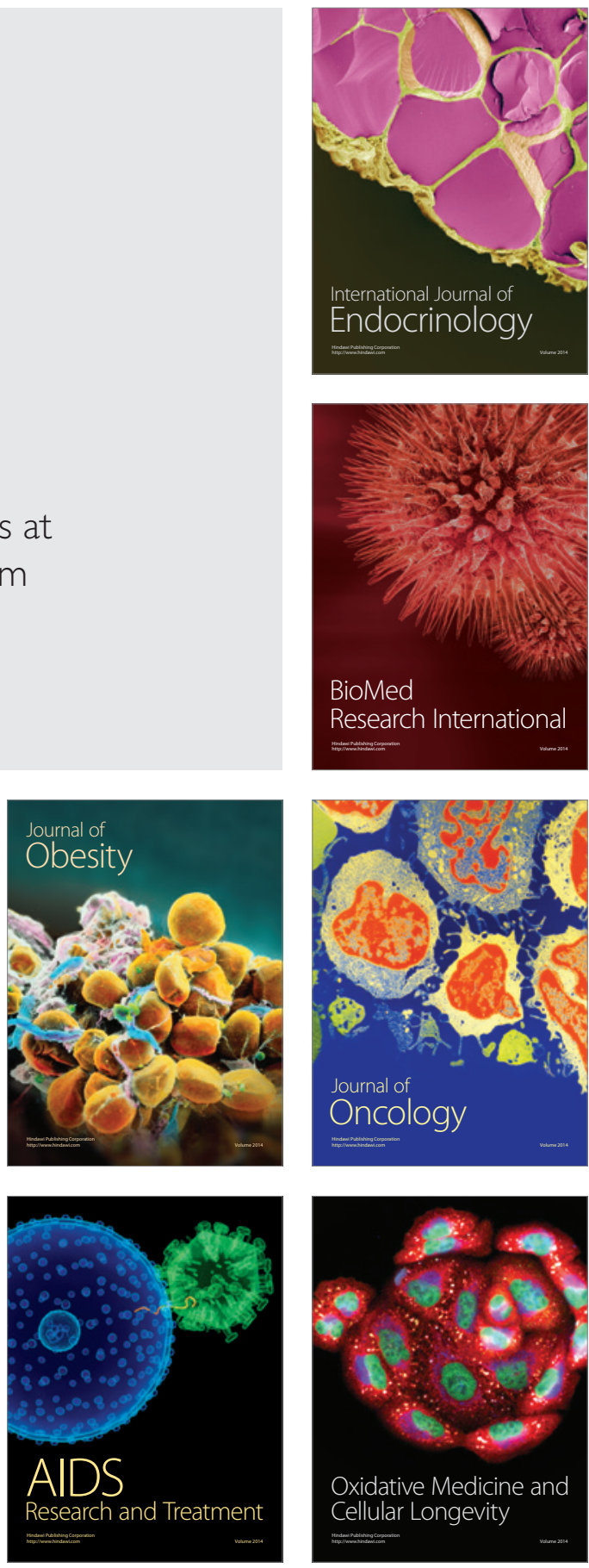